\title{
Characterization of the Key Aroma Compounds in the Fruit of Litsea pungens Hemsl. (LPH) by GC-MS/O, OAV, and Sensory Techniques
}

\author{
Dandan Pu $\mathbb{D}^{1},{ }^{1}$ Yimeng Shan $\left(\mathbb{D},{ }^{1}\right.$ Wen Duan $\left(\mathbb{D},{ }^{1}\right.$ Yan Huang $\mathbb{D}^{1},{ }^{1}$ Li Liang $\mathbb{D}^{1},{ }^{1}$ Yi Yan $\mathbb{D}^{1}$ \\ Yuyu Zhang $\mathbb{1},{ }^{1}$ Baoguo Sun $\mathbb{D}^{1},{ }^{1}$ and Guanghui $\mathrm{Hu} \mathbb{1}^{2}$ \\ ${ }^{1}$ Beijing Key Laboratory of Flavor Chemistry, Beijing Technology and Business University (BTBU), Beijing 100048, China \\ ${ }^{2}$ Beijing Center for Physical and Chemical Analysis, Beijing 100094, China \\ Correspondence should be addressed to Yuyu Zhang; zhangyuyu@btbu.edu.cn
}

Received 25 November 2020; Revised 3 February 2021; Accepted 24 March 2021; Published 13 April 2021

Academic Editor: Charfedinne Ayed

Copyright (c) 2021 Dandan Pu et al. This is an open access article distributed under the Creative Commons Attribution License, which permits unrestricted use, distribution, and reproduction in any medium, provided the original work is properly cited.

\begin{abstract}
The key aroma compounds in the fruit of Litsea pungens Hemsl. (LPH) were concentrated through solvent-assisted flavor evaporation (SAFE) and characterized by gas chromatography-mass spectrometry-olfactometry (GC-MS/O), quantitative descriptive analysis (QDA), odor activity values (OAVs), and addition test. The results showed that LPH contained 31 aroma-active compounds (flavor dilution, FD =9). Among them, 30 odorants were quantified by the standard curve method. The OAV analysis results showed that 25 odorants had OAVs $\geq 1$, which could be considered as the potent odorants. D-Limonene and 3,7-dimethyl2,6-octadienal had the highest OAVs (OAV= 9803 and 8399), followed by (Z)-3,7-dimethylocta-2,6-dienal (OAV=1893), $\beta$-myrcene $(\mathrm{OAV}=1798),(E)$-3-phenyl-2-propenoic acid ethyl $(\mathrm{OAV}=1603)$, and $\beta$-caryophyllene $(\mathrm{OAV}=1129)$. Addition experiments further confirmed that 3,7-dimethyl-2,6-octadienal, (Z)-3,7-dimethylocta-2,6-dienal, and D-limonene contributed to lemon attribute, $\beta$-myrcene contributed to green attribute, citronellal contributed to mint and fresh note, and eucalyptol contributed to eucalyptus-like note were the key odorants.
\end{abstract}

\section{Introduction}

Litsea pungens, as a genus belongs to Lauraceae's family, is an evergreen or deciduous tree or shrub with about 200 species distributed worldwide (mainly distributed in tropical and subtropical regions of Asia and America) [1]. In China, there are 72 species of Litsea pungens Hemsl. (LPH) distributed in 20 provinces (Figure 1). Among them, Yunnan Province has the most species (37), followed by Guangdong (24), Sichuan (18), Guizhou (15), and Hunan Province (12). The fruit, root, branch, and leaves of LPH have a wide range of applications in traditional Chinese medicine, fragrance industry $[2,3]$, cosmetics industry, and food industry due to the functional compounds existing inside, such as the aromatic compounds (essential oil), flavonoids, terpenoids, butanolides, and butenolactones steroids, lignans, amides, and alkaloids. The LPH, rich in citral, is an important raw material for ionone and damascene $[4,5]$. Due to the large and broad market demand, several decades ago, LPH species had been industrially cultivated, especially in Yunnan, Hubei, Hunan, Sichuan, Chongqing, and Guizhou provinces of China.

The therapeutic effects of LPH include removing dampness, regulating spleen deficiency, helping digestion, dysmenorrhea, expelling cold, and analgesia. All these benefits have been widely recorded in ancient Chinese medicine books such as "Guizhou folk medicine," "Chongqing Herbs," and "Hunan yaowuzhi." Modern molecular biology technologies have also elucidated that the functional compounds in the fruits, roots, branches, and leaves of LPH have anti-inflammatory activity, antimicrobial activity, hepatoprotection, antidiabetic, antiasthma activity, anticholelithiasis activity, immunomodulation, and miscellaneous bioactivities [3]. This information confirmed the 


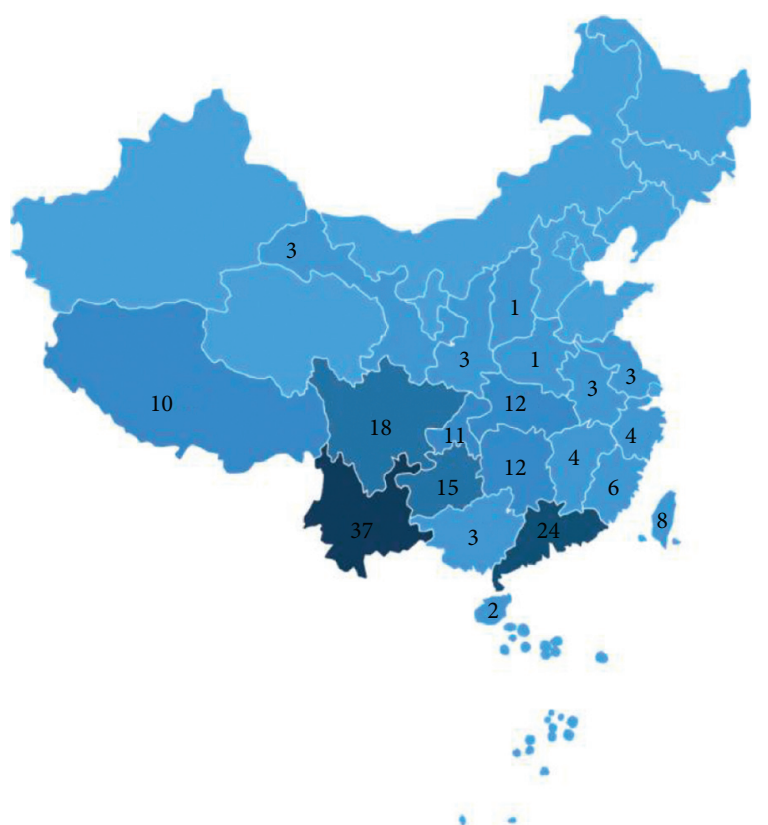

Figure 1: The area distribution of Litsea pungens Hemsl. [3-19]. Numbers presented in each province in the map of China represent the Litsea pungens Hemsl. species.

abundance of pharmacological properties of LPH. According to the Chinese natural spices classification standard (GB/T 21725-2017), LPH with a strong aroma is characterized as one of the 20 pungent type spices [20,21]. Based on its unique characteristics of citrus, sweet lemon, camphor wood, and green aroma, LPH is also a vital fragrance applied to many southwestern Chinese dishes, such as cooking beef or lamb, chili sauce, and pickled vegetables, especially the traditional Zhijiang Blood Duck (Huaihua, Hunan province) [6-8]. The LPH is an important pharmaceutical/food resource; therefore, elucidating the flavor chemistry of LPH is meaningful to the application of standardized LPH.

Up to now, five extraction methods have been applied to extract the aroma compounds in LPH's fruits, and more than 277 aroma compounds in LPH's fruit have been reported [4-19]. Most of them were terpenoids, which were the biomarkers of fruit freshness and ripeness [9]. However, only a small part $(1 \sim 3 \%)$ was the key odorants perceived in human olfaction $[22,23]$. Steam distillation (SD) was the most popular extraction method [11], followed by solidphase microextraction (SPME) [17], supercritical $\mathrm{CO}_{2}$ fluid extraction (SFE) [12], molecular distillation extraction (MDE) [18], and simultaneous distillation extraction (SDE) [10]. By applying SD coupled with gas chromatographymass spectrometry (GC-MS), (Z)-3,7-dimethyl-2,6-octadienal ( $\alpha$-citral), $(E)$-3,7-dimethyl-2,6-octadienal ( $\beta$-citral), D-limonene, terpinen-4-ol, (3Z)-3,7-dimethyl-2,6-octadiene-1-ol (nerol), 1,8-cineole, linalool, caryophyllene oxide, and 6-methyl-5-hepten-2-one were detected as the dominant aroma compounds in LPH's fruit [11-16]. Qiao et al. elucidated that $\alpha$-citral, $\beta$-citral, nerol, D-limonene, and 6methyl-5-hepten-2-one accounted for $90 \%$ of essential oil (extracted by SFE) of LPH's fruit, and citral was most prevalent (60\%). However, in fresh LPH's fruit [17], $\alpha$-citral and $\beta$-citral were most prevalent $(60.72 \%)$, followed by D-limonene $(24.17 \%), \quad \alpha$-pinene $(3.15 \%), \quad \beta$-myrcene $(2.92 \%)$, and $\beta$-pinene $(2.11 \%)$. Additionally, Qiao et al. $[17,18]$ reported that $\mathrm{D}$-limonene and citronellal accounted for $25.46 \%$ and $19.41 \%$ in LPH essential oils, respectively, by SPME-GC-MS analysis. Wang et al. confirmed that MDE has the higher extraction efficiency for fruit essential oils than other extraction methods suitable for industrial production [19]. Although the aroma compounds in LPH were qualitatively analyzed by mass spectrometry and quantified by area normalization method, the gas chromatographyolfactometry (GC-O) analysis and quantification by constructing the standard curves were not applied to screen the aroma-active compounds. Therefore, more efforts should be strengthened to characterize the key aroma compounds in LPH's fruit. Solvent-assisted flavor evaporation (SAFE) is the most suitable and useful extraction method for LPH's aroma analysis due to its high lipid content [24-26].

The objectives of this work are to identify the key aroma compounds in LPH's fruit by (1) isolating the volatile compounds from LPH's fruit by SAFE; (2) characterizing the aroma-active compounds by gas chromatography-mass spectrometry-olfactometry (GC-MS/O); and (3) quantifying the aroma-active compounds and calculating their OAVs. (4) Confirming the key odorants by addition experiment.

\section{Materials and Methods}

2.1. Sample Preparation. The dried LPH's fruit (August 2019) was purchased from Guiyang Qingshanbulao Litsea pungens Hemsl. Oil Factory (Guiyang, Guizhou, China). The moisture of dried LPH's fruit (7.08\%) was detected by a high-speed moisture analyzer (IR35M-000230 V1, Denver Instrument $\mathrm{GmbH}$, Göttingen, Germany) reference to our previous work $[27,28]$. Before determination, the LPH's fruit was powdered by grinder (Bangjie Machinery Equipment Factory, Wuxi, China).

2.2. Chemicals. 1,2-Dichlorobenzene and dichloromethane with GC grade were purchased from Thermo Fisher (Beijing, China). 3-Methylbutyric acid, 4-methylacetophenone, D-limonene, 2-octanol, decanoic acid, caryophyllene oxide, $\beta$-caryophyllene, $\beta$-myrcene, 6 -methyl-5-hepten-2-one, phenylacetic acid, and methional with purity over $99 \%$ were purchased from J\&K (Beijing, China). Ethyl p-methoxycinnamate, (E)-3-phenyl-2-propenoic acid ethyl, and safrole were bought from Beijing Zhongke Quality Inspection Biotechnology Co., Ltd. (Beijing, China). 3,7-Dimethyl-2,6octadienal, fenchone, (3Z)-3,7-dimethyl-2,6-octadien-1-ol, citronellal, eucalyptol, linalool, (E)-1-methyl-4-(1-methylvinyl)cyclohex-2-en-1-ol, 4-(1-methylethyl)-benzaldehyde, 2-(3-methyl-2-butenyl)-3-methylfuran, methyleugenol, D-carvone, carveol, (R)-2-methyl-5-((S)-6-methylhept-5en-2-yl)-cyclohexa-1,3-diene, estragole, (+)-2-bornanone, anethole, and (Z)-3,7-dimethylocta-2,6-dienal were purchased from Toronto Research Chemicals (Beijing, China). 
Eugenol and $p$-cresol were bought from Sigma-Aldrich (Beijing, China).

2.3. Sensory Evaluation. Quantitative descriptive analysis (QDA) was used to evaluate the aroma profiles of LPH's fruit. Twelve panelists with no rhinitis and no smoking (6 females and 6 males, age of 22-30) were recruited from our laboratory. The sensory evaluation room temperature was $23 \sim 25^{\circ} \mathrm{C}$, the humidity was $50 \sim 55 \%$, and filament lamp $(36 \mathrm{~W})$ was used. All panelists were informed of the aim, detailed experimental steps, and requirements of sensory evaluation before participating in this experiment. They were trained for 3 weeks before the QDA analysis: (1) all panelists were requested to sniff and describe the aroma characteristics of 54 -aroma kit (Le Nez du Vin ${ }^{\circledR}$, France) with 3 times a week (each training lasted for $30 \mathrm{~min}$ ); (2) then, panelists were requested to analyze the aroma profiles of LPH's fruit descriptively. The final 6 aroma attributes (lemon, floral and sweet, mint and fresh, green, eucalyptuslike, and sour) were determined according to the frequency of descriptors, and their corresponding referenced standards were D-limonene, nerol, menthol, 1-hexanol, 1,8-cineole, and propionic acid, respectively; (3) finally, 12 panelists were qualified to score the intensity of 6 aroma attributes on a scale from 1 to 9 (1-3, weak; $4-6$, medium; 7-9, strong). The LPH's fruit sample $(4.00 \mathrm{~g})$ loaded in $200 \mathrm{~mL}$ transparent glasses was presented to the panelist.

\subsection{Isolation of the Volatile Compounds by SAFE. Dried} LPH's fruit $(20.00 \pm 0.20 \mathrm{~g})$ and dichloromethane solvent $(80 \mathrm{~mL})$ were loaded in a conical flask $(250 \mathrm{~mL})$ and extracted for $15 \mathrm{~min}$ by ultrasonication (KH-500 DE, Jiangsu, China) in $500 \mathrm{~W}$ at $10^{\circ} \mathrm{C}$. Then, the organic phase was collected after filtration. After 3 extractions, the collected solvents were combined and submitted to the SAFE apparatus for volatile isolation. Isolation of the volatile compounds from the solvents was reference from our previous work with some modifications $[25,26]$. The recycled water in SAFE apparatus was $(40 \pm 1)^{\circ} \mathrm{C}$; the distillation flask was bath at $(40 \pm 1)^{\circ} \mathrm{C}$; the collection flask was immersed in liquid nitrogen; the extraction system was operated under vacuum $\left(10^{-5} \sim 10^{-6} \mathrm{~Pa}\right)$ via molecular turbine pump (Edwards, England), and the filtrate was added dropwise to the distillation flask. Then, the extract was concentrated to $1 \sim 2 \mathrm{~mL}$ with rotary evaporation instrument (EYELA N-1100, Tokyo Physical and Chemical Equipment Co., Ltd, Japan) after drying with anhydrous sodium sulfate. Finally, the concentrate was reduced to $1.00 \mathrm{~mL}$ by nitrogen (99.99\%) before GC-MS and GC-MS/O analysis. All analyses were repeated in triplicate.

2.5. GC-MS and GC-MS/O Analysis. The identification and quantification of the aroma compounds were conducted by a single quadrupole gas chromatograph-mass spectrometer (GC-MS) (Thermo Fisher Trace 1310, Thermo Fisher Technology Co., Ltd, USA) in a split ratio of 50:1 (optimized in our lab). The aroma-active compounds were screened by
GC-MS equipped with a sniffing port (ODP3, Gerstel, Germany) (GC-MS/O). The temperature of sniffing port was $220^{\circ} \mathrm{C}$, and the humidifier with flow rate of $10 \mathrm{~mL} / \mathrm{min}$ (nitrogen, 99.999\%) was used to humidify the air at sniffing port. The GC effluent was split at a ratio of $1: 1$ between the MS and sniffing port for the GC-MS/O's special structure in splitless injection. Separation of the aroma compounds in LPH's fruit extract was achieved on TG-5MS and TG-WAX columns (both $30 \mathrm{~m} \times 0.25 \mathrm{~mm}$ i.d. $\times 0.25 \mu \mathrm{m}$, Thermo Fisher). Helium (99.999\%) was the carrier gas, and the carrier gas flow rate was constant at $1.200 \mathrm{~mL} / \mathrm{min}$ and $2.000 \mathrm{~mL} / \mathrm{min}$ in GC-MS and GC-MS/O, respectively.

The oven temperature of TG-WAX column analyzer was initially held at $40^{\circ} \mathrm{C}$ for $2 \mathrm{~min}$, increased to $100^{\circ} \mathrm{C}$ (temperature rise rate, $4^{\circ} \mathrm{C} / \mathrm{min}$ ) and held for $1 \mathrm{~min}$, and then increased to $175^{\circ} \mathrm{C}$ (temperature rise rate, $2^{\circ} \mathrm{C} / \mathrm{min}$ ) and held for $1 \mathrm{~min}$, finally increased to $230^{\circ} \mathrm{C}$ (temperature rise rate, $5^{\circ} \mathrm{C} / \mathrm{min}$ ). The oven temperature of TG-5MS column analysis was initially held at $40^{\circ} \mathrm{C}$, then increased to $100^{\circ} \mathrm{C}$ (temperature rise rate, $3^{\circ} \mathrm{C} / \mathrm{min}$ ), increased to $170^{\circ} \mathrm{C}$ (temperature rise rate, $1^{\circ} \mathrm{C} / \mathrm{min}$ ) and held for $1 \mathrm{~min}$, and finally increased to $230^{\circ} \mathrm{C}$ (temperature rise rate, $5^{\circ} \mathrm{C} / \mathrm{min}$ ). The temperature of the sniffing port was kept at $230^{\circ} \mathrm{C}$. The injector temperature was $250^{\circ} \mathrm{C}$, and the ion source temperature was $280^{\circ} \mathrm{C}$. The electronic-impact mass spectra ionization mode with ionization energy of $70 \mathrm{eV}$ was used. The full scan mode ( $\mathrm{m} / z$ range from 40 to $350 \mathrm{amu}$ ) was used.

2.6. Gas Chromatography-Olfactometric (GC-O) Analysis. The aroma frequency, combined with the aroma dilution method, was used in the GC-O study. Firstly, the concentrated organic extract was diluted to $1: 9$ with dichloromethane solvent. The diluted sample was then submitted to the GC-MS/O with the TG-WAX column to screen the aroma-active compounds with flavor dilution (FD) factor over 9 . The diluted sample was repeated 3 times by 3 trained panelists. Only the aroma compounds detected over 5 of 9 were recorded. Panelists underwent GC-MS/O training by sniffing 31 standards aroma compounds in dichloromethane solvent $(1,000 \mu \mathrm{g} / \mathrm{L})$ three times before this experiment.

2.7. Identification and Quantification. The identification of the aroma compounds was based on comparing the mass spectra (MS) database NIST 2020, with retention indexes (RIs, on nonpolar and polar GC columns), pure standards $(\mathrm{S})$, and the odor characteristics $(\mathrm{O})$. All quantifications of key odorants were performed by constructing standard curves. The abscissa was referred to the ratio of the peak area of each compound to the three internal standards (1,2-dichlorobenzene, 2,500 $\mu \mathrm{g} / \mathrm{mL}$; 2-octanol, 2,900 $\mu \mathrm{g} / \mathrm{mL}$; 3methylacetophenone, $3,000 \mu \mathrm{g} / \mathrm{mL}$ ) that are obtained by GC-MS and the ordinate was the concentration ratio of aroma compounds to the three internal standards [29]. Each quantified aroma compound referenced from the specifically internal standard was labeled in Table 1. Each of the internal standards $(100 \mu \mathrm{L})$ was added when LPH's fruit was extracted by dichloromethane solvent. 
TABLE 1: Odor activity values $(\mathrm{OAVs})$ of aroma-active compounds $(\mathrm{FD}=9)$ in Litsea pungens Hemsl. fruit.

\begin{tabular}{|c|c|c|c|c|c|c|c|}
\hline No. & Compounds & CAS & $\begin{array}{l}\text { Concentration } \\
(\mu \mathrm{g} / \mathrm{kg})\end{array}$ & $\begin{array}{c}\text { Threshold } \\
(\mu \mathrm{g} / \mathrm{kg})\end{array}$ & OAV & Standard curves & $R^{2}$ \\
\hline 5 & D-Limonene ${ }^{c}$ & $5989-27-5$ & $333,321.19 \pm 1,339.09$ & $34[30]$ & 9803 & $y=0.0539 x-0.0014$ & 0.9932 \\
\hline 20 & 3,7-Dimethyl-2,6-octadienal ${ }^{\mathrm{a}}$ & $5392-40-5$ & $251,978.13 \pm 683.24$ & $30[31]$ & 8399 & $y=0.0851 x+0.0288$ & 0.9936 \\
\hline 17 & (Z)-3,7-Dimethylocta-2,6-dienal ${ }^{\mathrm{a}}$ & $106-26-3$ & $189,366.87 \pm 7,528.88$ & $100[31]$ & 1893 & $y=0.074 x+0.0085$ & 0.9958 \\
\hline 3 & $\beta$-Myrcene ${ }^{\mathrm{a}}$ & $123-35-3$ & $179,800.17 \pm 4,978.31$ & $100[32]$ & 1798 & $y=0.0896 x-0.0085$ & 0.9975 \\
\hline 28 & (E)-3-Phenyl-2-propenoic acid ethyl ${ }^{\mathrm{b}}$ & $4192-77-2$ & $6,913.31 \pm 913.99$ & $4[31]$ & 1603 & $y=0.1055 x+0.0146$ & 0.9975 \\
\hline 26 & $\beta$-Caryophyllene ${ }^{\mathrm{b}}$ & $87-44-5$ & $76,771.87 \pm 1,296.43$ & $64[30]$ & 1129 & $y=0.068 x+0.0212$ & 0.9837 \\
\hline 12 & Citronellal $^{\mathrm{a}}$ & $106-23-0$ & $25,397.45 \pm 1,483.47$ & $31[30]$ & 819 & $y=0.0487 x+0.008$ & 0.9972 \\
\hline 7 & Linalool $^{\mathrm{a}}$ & $78-70-6$ & $360,841.19 \pm 7,836.63$ & $500[32]$ & 722 & $y=0.073 x+0.0067$ & 0.9944 \\
\hline 4 & 6-Methyl-5-hepten-2-one ${ }^{a}$ & $110-93-0$ & $29,118.53 \pm 9,49.40$ & $50[32]$ & 582 & $y=0.094 x-0.0003$ & 0.9999 \\
\hline 2 & Methional $^{\mathrm{a}}$ & $3268-49-3$ & $890.48 \pm 177.02$ & $1.8[33]$ & 494 & $y=0.4585 x+0.004$ & 0.995 \\
\hline 13 & Estragole $^{\mathrm{b}}$ & $140-67-0$ & $13,376.54 \pm 3,255.45$ & $35[31]$ & 382 & $y=0.0875 x-0.004$ & 0.9964 \\
\hline 6 & Eucalyptol $^{\mathrm{b}}$ & $470-82-6$ & $81,581.26 \pm 1,136.85$ & $230[31]$ & 355 & $y=0.0613 x+0.0025$ & 0.9987 \\
\hline 11 & 2-(3-Methyl-2-butenyl)-3-methylfuran ${ }^{c}$ & $15186-51-3$ & $23,794.84 \pm 4,610.74$ & $100[31]$ & 238 & $y=0.0384 x+0.0058$ & 0.9979 \\
\hline 21 & Anethole $\mathrm{b}^{\mathrm{b}}$ & $104-46-1$ & $7,133.33 \pm 551.68$ & $50[31]$ & 143 & $y=0.062 x+0.0085$ & 0.9993 \\
\hline 23 & Eugenol $^{\mathrm{b}}$ & $97-53-0$ & $10,249.40 \pm 824.78$ & $90[31]$ & 114 & $y=0.0988 x-0.0039$ & 0.9882 \\
\hline 18 & D-Carvone ${ }^{c}$ & $2244-16-8$ & $6,998.14 \pm 682.58$ & $160[31]$ & 44 & $y=0.1175 x+0.0262$ & 0.9936 \\
\hline 25 & Methyleugenol $^{\mathrm{b}}$ & $93-15-2$ & $2,529.33 \pm 467.25$ & $68[31]$ & 37 & $y=0.0696 x+0.011$ & 0.9977 \\
\hline 9 & $p$-Cresol ${ }^{\mathrm{b}}$ & $106-44-5$ & $3,229.82 \pm 41.03$ & $100[32]$ & 32 & $y=0.0429 x+0.0248$ & 0.9928 \\
\hline 22 & Safrole ${ }^{\mathrm{b}}$ & $94-59-7$ & $2,328.99 \pm 390.14$ & $160[31]$ & 15 & $y=0.0797 x+0.0141$ & 0.9978 \\
\hline 16 & 4-(1-methylethyl)-benzaldehyde ${ }^{b}$ & $122-03-2$ & $2,500.23 \pm 157.00$ & $177[31]$ & 14 & $y=0.0612 x+0.0183$ & 0.9961 \\
\hline 15 & (3Z)-3,7-Dimethyl-2,6-octadien-1-ol ${ }^{\mathrm{a}}$ & $106-25-2$ & $3,747.99 \pm 643.73$ & $300[30]$ & 12 & $y=0.1214 x-0.006$ & 0.9983 \\
\hline 31 & Ethyl $p$-methoxycinnamate & $24393-56-4$ & $5,422.92 \pm 244.75$ & $500[34]$ & 11 & $y=0.1576 x+0.0407$ & 0.9956 \\
\hline 30 & Caryophyllene oxide $\mathrm{e}^{\mathrm{b}}$ & $1139-30-6$ & $3,829.05 \pm 630.81$ & $400[31]$ & 10 & $y=0.0412 x+0.0156$ & 0.9837 \\
\hline 27 & $(+)-2$-Bornanone $e^{d}$ & $464-49-3$ & $3,802.95 \pm 770.73$ & $1360[31]$ & 3 & $y=0.0482 x-0.007$ & 0.9962 \\
\hline 1 & 3-Methyl-butryicacid ${ }^{\mathrm{a}}$ & $503-74-2$ & $156.40 \pm 3.15$ & $100[31]$ & 1.5 & $y=0.1128 x-0.0033$ & 0.9982 \\
\hline 10 & Fenchone $e^{c}$ & $1195-79-5$ & $97.44 \pm 11.68$ & $440[31]$ & $<1$ & $y=0.0482 x-0.007$ & 0.9962 \\
\hline 14 & Carveol $^{\mathrm{c}}$ & $99-48-9$ & $665.79 \pm 637.26$ & $4000[35]$ & $<1$ & $y=0.4792 x-3 E-19$ & 0.9999 \\
\hline 24 & Decanoic acid ${ }^{\mathrm{a}}$ & $334-48-5$ & $2,043.84 \pm 670.91$ & $2200[32]$ & $<1$ & $y=0.084 x+0.0068$ & 0.9943 \\
\hline 29 & $\begin{array}{l}(R) \text {-2-Methyl-5- }((S) \text {-6-methylhept-5-en- } \\
\text { 2-yl)-cyclohexa-1,3-diene }\end{array}$ & $495-60-3$ & $9,925.30 \pm 535.49$ & - & - & $y=0.0875 x-0.004$ & 0.9964 \\
\hline 19 & Phenylacetic acid $^{\mathrm{c}}$ & $103-82-2$ & - & & - & - & - \\
\hline 8 & $\begin{array}{c}(E)-1-\text { methyl-4-(1-methylvinyl)cyclohex- } \\
2 \text {-en-1-ol }{ }^{\mathrm{c}}\end{array}$ & $7212-40-0$ & $10,040.07 \pm 468.85$ & - & - & $y=0.0765 x-1 E-04$ & 0.9991 \\
\hline
\end{tabular}

The alphabet a, b, c, and d represent compounds calibration by internal standard compounds of 2-octanol, 1,2-dichlorobenzene, and $4^{\prime}$-methylacetophenone, respectively; "-" represents the aroma compounds were lower than the quantitative limitation.

2.8. Calculation of the Odor Activity Value (OAV). The OAVs of aroma-active compounds were measured by dividing their concentration detected in the LPH's fruit sample by their odor threshold detected in water. Each threshold value was referenced from the corresponding literature studies and book, which labeled in Table $1[30-33,36,37]$. The aroma-active compounds with $\mathrm{OAV} \geq 1$ are considered to be the potent key odorants of LPH fruit.

2.9. Addition Experiment. The addition tests were conducted to validate the potent odorants and elucidate their specifically contributions with high OAV to LPH's fruit sample by adding the aroma compounds to the LPH's fruit sample $(5.00 \mathrm{~g})$ based on the detected concentration. Two original LPH's fruit samples $(5.00 \mathrm{~g})$ and one aroma added sample were subjected to the panelists. Panelists were requested to evaluate the difference by triangle tests and quantitative descriptive analysis (Section 2.3) [38] as shown in Table 2.

\section{Results and Discussion}

3.1. Sensory Evaluation. The QDA result data of LPH's fruit were plotted on a spider diagram shown in Figure 2, suggesting that lemon note was the strongest, followed by floral and sweet, mint and fresh, eucalyptus-like, and green characteristics. The sour note of LPH's fruit had the lowest intensity. This result also elucidated the LPH's fruit had a potent flavor enhancer or improving ability.

3.2. Aroma Compounds in LPH's Fruit. In this work, a total of 159 volatile compounds including 55 olefins, 34 alcohols, 10 aldehydes, 8 acids, 18 ketones, 14 esters, 7 phenolics, 4 furans, 3 alkanes, 3 ethers, and 3 sulfur compounds were detected by SAFE-GC-MS analysis (Table S1). Among the 55 olefins, terpenoids were the most prevalent substances, including the monoterpenes (C10), sesquiterpenes (C15), and diterpenes (C20). These plant-derived compounds were biosynthesized from the active isoprene C5 units 
TABLE 2: Results of the addition tests.

\begin{tabular}{|c|c|c|c|c|}
\hline No. & Omitted compounds & Correct numbers & Significance $^{\mathrm{a}}$ & Contribution aroma \\
\hline 1 & D-Limonene & $9 / 12$ & * & Lemon \\
\hline 2 & 3,7-Dimethyl-2,6-octadienal & $12 / 12$ & $* *$ & Lemon \\
\hline 3 & (Z)-3,7-Dimethylocta-2,6-dienal & $12 / 12$ & $* *$ & Lemon \\
\hline 4 & $\beta$-Myrcene & $10 / 12$ & $* *$ & Green \\
\hline 5 & (E)-3-Phenyl-2-propenoic acid ethyl & $5 / 12$ & & \\
\hline 6 & $\beta$-Caryophyllene & $5 / 12$ & & \\
\hline 7 & Citronellal & $12 / 12$ & $* *$ & Mint and fresh \\
\hline 8 & Linalool & $11 / 12$ & $*$ & Floral and sweet \\
\hline 9 & 6-Methyl-5-hepten-2-one & $8 / 12$ & & \\
\hline 10 & Methional & $7 / 12$ & & \\
\hline 11 & Estragole & $5 / 12$ & & \\
\hline 12 & Eucalyptol & $11 / 12$ & $* *$ & Eucalyptus-like \\
\hline 13 & 2-(3-Methyl-2-butenyl)-3-methylfuran & $8 / 12$ & & \\
\hline 14 & Anethole & $8 / 12$ & & \\
\hline 15 & Eugenol & $6 / 12$ & & \\
\hline
\end{tabular}

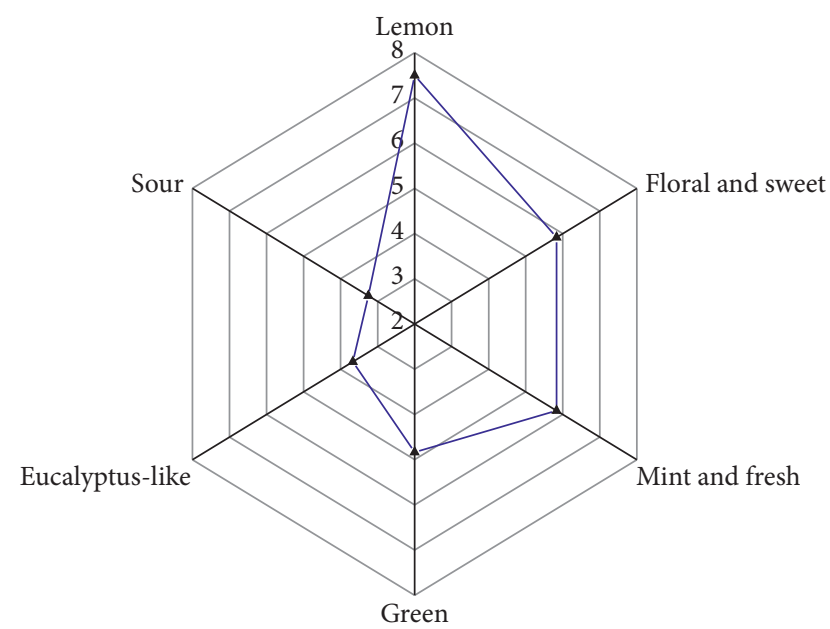

Figure 2: Aroma profiles of Litsea pungens Hemsl. fruit by quantitative descriptive analysis.

dimethylallyl diphosphate and isopentenyl diphosphate, which belong to the most diverse family of natural products $[39,40]$. As the results showed, $\alpha$-pinene, camphene, $\beta$-myrcene, $\alpha$-phellandrene, 3-carene, D-limonene, $(Z)-3,7$ dimethyl-1,3,6-octatriene, $\gamma$-terpinene, $p$-mentha-1,4(8)diene, $\beta$-ocimene, and $o$-cymene were monoterpenes (C10); (Z)- $\alpha$-bergamotene, humulene, copaene, caryophyllene, guaia-1(10),11-diene, $\quad(E, E)-1$-methyl-5-methylene-8-(1methylethyl)-1,6-cyclodecadiene, (E)- $\beta$-famesene, $\alpha$-cubebene, $\alpha$-guaiene, and $\beta$-bisabolene were sesquiterpenes (C15). On the contrary, only one diterpene $(2,6,11,15$-tetramethyl-hexadeca-2,6,8,10,14-pentaene) was detected in LPH's fruit. These results elucidated that the most of the volatile terpenoids were mono and sesquiterpenes with only a few diterpenes [40, 41]. Applying isotope-labeled pathwayspecific precursors and green fluorescent protein-labeled terpene synthases have shown that monoterpenes' biosynthesis was located in plastids and fueled by the methylerythritol phosphate pathway. In contrast, the biosynthesis of sesquiterpenes was located in the cytosol and fueled by the cytosolic/peroxisomal mevalonic acid pathway and, under certain conditions, the methylerythritol phosphate pathway via the abovementioned metabolic crosstalk [42]. Acyclic (geraniol, linalool, and myrcene), monocyclic (D-limonene and $\alpha$-terpineol), and bicyclic (car-3-ene and $\alpha$-pinene) monoterpenes were biosynthesis from geranyl diphosphate by terpene synthases that shared a coupled isomerizationcyclization reaction sequence [42]. These compounds were usually found in plant-derived monoterpenes. Carvone could be generated by a series of enzyme-catalyzed synthesis, including geranyl diphosphate synthase, (-)-limonene synthase, (-)-limonene 6-hydroxylase, and (-)-trans-carveol dehydrogenase [43]. $\beta$-Caryophyllene was derived from farnesyl diphosphate by sesquiterpene cyclization reactions leading to volatile sesquiterpene hydrocarbons [44].

The chain acids, such as acetic acid, 3-methyl-butyric acid, and decanoic acid, were derived from the degradation of fatty acids. Phenylacetic acid was generated from L-phenylalanine via the shikimic acid pathway under the action of phenylalanine ammonia-lyase. Esters in the plants mainly generated from two ways: alcohol acyltransferase and carboxylesterase, belonging to the biosynthesis of amino acid-derived odor compounds [45]. Three kinds of ketone, including sesquiterpenes ketones, furan ketones, and chain ketones, were detected in the LPH's fruit. Sesquiterpenes ketones were mainly derived from the biosynthesis of the terpenoid pathway; furan ketones were carbohydrate-derived or carotenoid-derived volatile compounds, and chain ketones generated from lipids degradation [46]. The phenolic compounds were mainly derived from L-phenylalanine. Cinnamic acid was generated under the action of a phenylalanine ammonia-lyase, and then cinnamic aldehyde produced though reduction reaction [47]. Aldehydes with fresh green characteristics were mainly derived from the fatty acids (linolenic acid) by the lipoxygenase pathway [45]. Generally, the fatty acids were stored in plants as triacylglycerides and were liberated by lipases before they are acted as direct precursors for various volatiles. The sulfur compounds were derived from amino acid degradation [36]. Most of the alcoholics (monoterpenes), such as (3Z)-3,7- 
TABLE 3: Qualitative analysis results of aroma-active compounds $(F D=9)$ in Litsea pungens Hemsl. fruit.

\begin{tabular}{|c|c|c|c|c|c|c|}
\hline No. & Compounds & CAS & Structure & $\begin{array}{c}\text { RI (TG-5MS/ } \\
\text { TG-WAX) }\end{array}$ & Aroma descriptions & Identification \\
\hline 1 & 3-Methyl-butryicacid & $503-74-2$ & & $863 / 859$ & Sour, sweaty, cheese & $\mathrm{MS} / \mathrm{RI} / \mathrm{S} / \mathrm{O}$ \\
\hline 2 & Methional & $3268-49-3$ & & $903 / 906$ & Cooked potato & $\mathrm{MS} / \mathrm{RI} / \mathrm{S} / \mathrm{O}$ \\
\hline 3 & $\beta$-Myrcene & $123-35-3$ & & $989 / 990$ & Spicy, peppery, green & $\mathrm{MS} / \mathrm{RI} / \mathrm{S} / \mathrm{O}$ \\
\hline 4 & 6-Methyl-5-hepten-2-one & $110-93-0$ & & $991 / 986$ & Citrus, green, musty & $\mathrm{MS} / \mathrm{RI} / \mathrm{S} / \mathrm{O}$ \\
\hline 5 & D-Limonene & $5989-27-5$ & & $1027 / 1039$ & $\begin{array}{l}\text { Citrus, orange, fresh, } \\
\text { sweet }\end{array}$ & $\mathrm{MS} / \mathrm{RI} / \mathrm{S} / \mathrm{O}$ \\
\hline 6 & Eucalyptol & $470-82-6$ & & $1032 / 1029$ & $\begin{array}{l}\text { Eucalyptus, camphor, } \\
\text { medicine }\end{array}$ & $\mathrm{MS} / \mathrm{RI} / \mathrm{S} / \mathrm{O}$ \\
\hline 7 & Linalool & $78-70-6$ & & $1104 / 1116$ & $\begin{array}{l}\text { Floral, sweet, woody, } \\
\text { green }\end{array}$ & $\mathrm{MS} / \mathrm{RI} / \mathrm{S} / \mathrm{O}$ \\
\hline 8 & $\begin{array}{l}\text { (E)-1-Methyl-4-(1-methylvinyl)cyclohex- } \\
\text { 2-en-1-ol }\end{array}$ & $7212-40-0$ & & $1105 / 1127$ & Fresh, minty, woody & $\mathrm{MS} / \mathrm{RI} / \mathrm{S} / \mathrm{O}$ \\
\hline 9 & $p$-Cresol & $106-44-5$ & & $1085 / 1076$ & Phenolic, leather, animal & $\mathrm{MS} / \mathrm{RI} / \mathrm{S} / \mathrm{O}$ \\
\hline 10 & Fenchone & $1195-79-5$ & & $1090 / 1083$ & Fresh, woody & $\mathrm{MS} / \mathrm{RI} / \mathrm{S} / \mathrm{O}$ \\
\hline 11 & 2-(3-Methyl-2-butenyl)-3-methylfuran & $15186-51-3$ & & $1093 / 1100$ & Caramel, sweet, floral & $\mathrm{MS} / \mathrm{RI} / \mathrm{S} / \mathrm{O}$ \\
\hline 12 & Citronellal & $106-23-0$ & & $1151 / 1156$ & Sweet, floral, citrus & $\mathrm{MS} / \mathrm{RI} / \mathrm{S} / \mathrm{O}$ \\
\hline 13 & Estragole & $140-67-0$ & & $1196 / 1204$ & $\begin{array}{l}\text { Spicy, green, herbal, } \\
\text { fennel }\end{array}$ & $\mathrm{MS} / \mathrm{RI} / \mathrm{S} / \mathrm{O}$ \\
\hline 14 & Carveol & $99-48-9$ & & $1225 / 1210$ & Spearmint, caraway & $\mathrm{MS} / \mathrm{RI} / \mathrm{S} / \mathrm{O}$ \\
\hline 15 & (3Z)-3,7-Dimethyl-2,6-octadien-1-ol & $106-25-2$ & & $1236 / 1225$ & $\begin{array}{l}\text { Sweet, floral, citrus, } \\
\text { magnolia }\end{array}$ & $\mathrm{MS} / \mathrm{RI} / \mathrm{S} / \mathrm{O}$ \\
\hline 16 & 4-(1-Methylethyl)-benzaldehyde & $122-03-2$ & & $1239 / 1233$ & $\begin{array}{l}\text { Spicy, cumin, green, } \\
\text { herbal }\end{array}$ & $\mathrm{MS} / \mathrm{RI} / \mathrm{S} / \mathrm{O}$ \\
\hline 17 & (Z)-3,7-Dimethylocta-2,6-dienal & $106-26-3$ & & $1242 / 1254$ & $\begin{array}{l}\text { Floral, sweet, citral, } \\
\text { lemon }\end{array}$ & $\mathrm{MS} / \mathrm{RI} / \mathrm{S} / \mathrm{O}$ \\
\hline 18 & D-Carvone & $2244-16-8$ & & $1246 / 1255$ & Spicy, mint, green & $\mathrm{MS} / \mathrm{RI} / \mathrm{S} / \mathrm{O}$ \\
\hline 19 & Phenylacetic acid & $103-82-2$ & & $1262 / 1274$ & Sweet, honey, floral & $\mathrm{MS} / \mathrm{RI} / \mathrm{S} / \mathrm{O}$ \\
\hline 20 & 3,7-Dimethyl-2,6-Octadienal & $5392-40-5$ & & $1276 / 1290$ & Lemon, sweet, citura & $\mathrm{MS} / \mathrm{RI} / \mathrm{S} / \mathrm{O}$ \\
\hline 21 & Anethole & $104-46-1$ & & $1279 / 1298$ & Anise, licorice, medicinal & $\mathrm{MS} / \mathrm{RI} / \mathrm{S} / \mathrm{O}$ \\
\hline 22 & Safrole & $94-59-7$ & & $1287 / 1264$ & $\begin{array}{l}\text { Spicy, woody, floral, } \\
\text { anise }\end{array}$ & $\mathrm{MS} / \mathrm{RI} / \mathrm{S} / \mathrm{O}$ \\
\hline 23 & Eugenol & $97-53-0$ & & $1348 / 1361$ & $\begin{array}{l}\text { Clove, sweet, spicy, } \\
\text { woody }\end{array}$ & $\mathrm{MS} / \mathrm{RI} / \mathrm{S} / \mathrm{O}$ \\
\hline 24 & Decanoic acid & $334-48-5$ & & $1373 / 1423$ & Rancid sour, fatty, waxy & $\mathrm{MS} / \mathrm{RI} / \mathrm{S} / \mathrm{O}$ \\
\hline 25 & Methyleugenol & $93-15-2$ & & $1404 / 1411$ & $\begin{array}{l}\text { Sweet, fresh, spicy, clove, } \\
\text { cinnamon }\end{array}$ & $\mathrm{MS} / \mathrm{RI} / \mathrm{S} / \mathrm{O}$ \\
\hline 26 & $\beta$-Caryophyllene & $87-44-5$ & & $1420 / 1424$ & $\begin{array}{l}\text { Clove, sweet, woody, } \\
\text { spicy }\end{array}$ & $\mathrm{MS} / \mathrm{RI} / \mathrm{S} / \mathrm{O}$ \\
\hline
\end{tabular}


TABLE 3: Continued.

\begin{tabular}{|c|c|c|c|c|c|c|}
\hline No. & Compounds & CAS & Structure & $\begin{array}{l}\text { RI (TG-5MS/ } \\
\text { TG-WAX) }\end{array}$ & Aroma descriptions & Identification \\
\hline 27 & $(+)$-2-Bornanone & $464-49-3$ & & $1443 / 1143$ & $\begin{array}{l}\text { Camphor, minty, herbal, } \\
\text { woody }\end{array}$ & $\mathrm{MS} / \mathrm{RI} / \mathrm{S} / \mathrm{O}$ \\
\hline 28 & (E)-3-Phenyl-2-propenoic acid ethyl & $4192-77-2$ & & $1474 / 1463$ & $\begin{array}{l}\text { Floral, honey, balsamic, } \\
\text { wine }\end{array}$ & $\mathrm{MS} / \mathrm{RI} / \mathrm{S} / \mathrm{O}$ \\
\hline 29 & $\begin{array}{l}\text { (R)-2-Methyl-5-((S)-6-methylhept-5-en-2- } \\
\text { yl)-cyclohexa-1,3iene }\end{array}$ & $495-60-3$ & & $1500 / 1494$ & Spicy, fresh, sharp woody & $\mathrm{MS} / \mathrm{RI} / \mathrm{S} / \mathrm{O}$ \\
\hline 30 & Caryophyllene oxide & $1139-30-6$ & & $1561 / 1543$ & $\begin{array}{l}\text { Sweet, fresh, woody, } \\
\text { spicy }\end{array}$ & $\mathrm{MS} / \mathrm{RI} / \mathrm{S} / \mathrm{O}$ \\
\hline 31 & Ethyl p-methoxycinnamate & $24393-56-4$ & & $1773 / 1748$ & Cinnamon, sweet, wine & $\mathrm{MS} / \mathrm{RI} / \mathrm{S} / \mathrm{O}$ \\
\hline
\end{tabular}

"MS," compounds were identified by mass spectra (NIST 14); "RI," compounds were identified on TG-WAX and TG-5MS columns; "S," compounds were identified by standards; "O," compounds were identified by GC-O.

dimethyl-2,6-octadiene-1-ol, (E)-linalool oxide, (E)-4-thujanol, and (E)-p-mentha-2,8-dien-1-ol were derived from the precursor of granyl diphosphate, whereas the sesquiterpenes alcoholics including nerolidol and decahydro-1,4dimethyl-7-(1-methylvinyl)azulen-4-ol were derived from the precursor of $(E, E)$-farnesyl diphosphate [47].

These volatile compounds with the properties of sweet, floral, citrus, green, herb, fresh, eucalyptus, phenolic, spicy, and sour characteristics also had an antimicrobial activity or other biological functional activities. They were detected in LPH's fruits and existed in the roots, stems, and leaves, which played an important role in plant-animal interactions, including the attraction of pollinators and seed disseminators, protecting the plants from pathogen attack, and repellence of herbivores [36].

3.3. Quantitation and Calculation of the Odor Active Values $(O A V s)$. A total of 31 aroma-active compounds $(\mathrm{FD}=9)$ were detected by gas chromatography-olfactory. Among them, terpenoids (16) were the most prevalent. $\beta$-Myrcene, linalool, and citronellal were acyclic monoterpenes. D-limonene, carveol, eucalyptol, and D-carvone were monocyclic monoterpenes; $(+)$-2-bornanone and fenchone were bicyclic monoterpenoids; (3Z)-3,7-dimethyl-2,6-octadien-1-ol (nerolidol) was acyclic sesquiterpenes; $\beta$-caryophyllene, caryophyllene, and (R)-2-methyl-5- $((S)-6$ methylhept-5-en-2-yl)-cyclohexa-1,3-diene oxide were bicyclic sesquiterpenes. These compounds with spicy, floral, green, fresh, woody, citrus, and herb spearmint characteristics consist of the main aroma profiles of LPH's fruits. The other compounds, such as acids, phenolics, and esters, also played an important role in the overall aroma profiles.

To confirm the potent aroma compounds in the overall aroma profiles of LPH's fruit, the aroma-active compounds were quantified, and their odor activity values (OAVs, the ratio of concentration to odor threshold) were also calculated. The standard curves of each aroma-active compound are shown in Table 1. All the calibration curves obtained had good linearity $\left(R^{2}>0.99\right)$. Quantification results showed (Table 3) that linalool had the highest concentration $(360,841.19 \mu \mathrm{g} / \mathrm{kg})$, followed by D-limonene $(333,321.19 \mu \mathrm{g} /$ $\mathrm{kg})$, 3,7-dimethyl-2,6-octadienal $(251,978.13 \mu \mathrm{g} / \mathrm{kg}),(Z)-3,7$ dimethylocta-2,6-dienal $\quad(189,366.87 \mu \mathrm{g} / \mathrm{kg}), \quad \beta$-myrcene $(179,800.17 \mu \mathrm{g} / \mathrm{kg})$, eucalyptol $(81,581.26 \mu \mathrm{g} / \mathrm{kg})$, and $\beta$-caryophyllene $(76,771.87 \mu \mathrm{g} / \mathrm{kg})$. Fenchone $(97.44 \mu \mathrm{g} / \mathrm{kg})$ and 3methyl-butyric acid $(156.40 \mu \mathrm{g} / \mathrm{kg})$ had the lowest concentrations.

As the OAV analysis results shown above, there were 25 odorants with OAVs $\geq 1$ in LPH's fruit, but 3 compounds (fenchone, carveol, and decanoic acid) had OAVs $<1$, indicating that they were not the potent odorants in the overall aroma of LPH's fruit. The odor threshold value of $(E)-1-$ methyl-4-(1-methylvinyl) cyclohex-2-en-1-ol and $(R)-2$ methyl-5-((S)-6-methylhept-5-en-2-yl)-cyclohexa-1,3-diene was not found; therefore, their OAVs were not calculated. Moreover, the concentration of phenylacetic acid was lower than the limit of quantitation. The remained 25 odorants with OAVs ranged from 1.5 to 9803 were the potent odorants for LPH's fruit aroma. Among them, D-limonene had the highest OAV $(\mathrm{OAV}=9803)$ for its significant high concentration and low threshold $(34 \mu \mathrm{g} / \mathrm{kg})$, followed by $3,7-$ dimethyl-2,6-octadienal (OAV=8399), (Z)-3,7-dimethylocta-2,6-dienal $(\mathrm{OAV}=1893), \beta$-myrcene $(\mathrm{OAV}=1798)$, $(E)$-3-phenyl-2-propenoic acid ethyl $(\mathrm{OAV}=1603), \beta$-caryophyllene $(\mathrm{OAV}=1129)$, citronellal $(\mathrm{OAV}=819)$, linalool $(\mathrm{OAV}=722), \quad 6$-methyl-5-hepten-2-one $\quad(\mathrm{OAV}=582)$, methional $(\mathrm{OAV}=494)$, estragole $(\mathrm{OAV}=382)$, eucalyptol $(\mathrm{OAV}=355), \quad$ 2-(3-methyl-2-butenyl)-3-methylfuran $(\mathrm{OAV}=238)$, anethole $(\mathrm{OAV}=143)$, and eugenol $(\mathrm{OAV}=114)$. Interestingly, most of the terpenoids exhibited higher OAVs, which are similar to other species, for example, Toona sinensis (A. Juss.) and pepper (Zanthoxylum bungeanum) $[30,37]$. The results of aroma characteristics quality, OAV analysis, and the sensory evaluation elucidated that D-limonene, citronellal, 3,7-dimethyl-2,6-octadienal, (Z)-3,7-dimethylocta-2,6-dienal, (E)-3-phenyl-2-propenoic acid ethyl, $\beta$-myrcene, linalool, methional, 6-methyl-5- 
hepten-2-one, 2-(3-methyl-2-butenyl)-3-methylfuran, $\beta$-caryophyllene, estragole, anethole, eucalyptol, and eugenol might be the key odorants of LPH's fruit.

3.4. Addition Experiment. Addition tests results elucidated that 3,7-dimethyl-2,6-octadienal and (Z)-3,7-dimethylocta2,6-dienal had high significant $(P<0.001)$ contribution to the lemon attribute of LPH's fruit. Besides, D-limonene also had contribution to lemon attribute $(P<0.05) . \beta$-Myrcene had high significant $(P<0.001)$ contribution to the green attribute of LPH's fruit. Citronellal had high significant $(P<0.001)$ contribution to the mint and fresh attribute. Eucalyptol had high significant $(P<0.001)$ contribution to the eucalyptus-like note of LPH's fruit. In summary, 3,7dimethyl-2,6-octadienal and (Z)-3,7-dimethylocta-2,6dienal, D-limonene, $\beta$-myrcene, citronellal, and eucalyptol were confirmed as the key odorants of LPH's fruit. As the significant difference results elucidated, 3,7-dimethyl-2,6octadienal and (Z)-3,7-dimethylocta-2,6-dienal were greater than that of D-limonene.

\section{Conclusions}

The aroma compounds in LPH's fruit were isolated by SAFE. By application of frequency combined with aroma dilution analysis, 31 aroma-active compounds were detected, and 30 of them were further quantified by the external standard method. OAVs $\geq 1$ were obtained for 25 odorants among which D-limonene (OAV =9803) and 3,7-dimethyl-2,6-octadienal $(\mathrm{OAV}=8399)$ had the highest OAV value. (Z)-3,7-dimethylocta-2,6-dienal $(\mathrm{OAV}=1893), \beta$-myrcene $(\mathrm{OAV}=1798),(E)$-3-phenyl-2propenoic acid ethyl $(\mathrm{OAV}=1603)$, and $\beta$-caryophyllene $(\mathrm{OAV}=1129)$ had OAV over 1000 . These results elucidated that they played an important role to the overall aroma profiles if LPH's fruit. Based on the addition tests, 3,7-dimethyl-2,6-octadienal and (Z)-3,7-dimethylocta2,6-dienal and D-limonene contributing to lemon attribute, $\beta$-myrcene contributing to green attribute, citronellal contributing to mint and fresh note, and eucalyptol contributing to eucalyptus-like note were confirmed as the key odorants in LPH's fruit.

\section{Data Availability}

All the date used in this work could be found in the manuscript and the supplemental materials.

\section{Conflicts of Interest}

The authors declare that they have no conflicts of interest.

\section{Acknowledgments}

This work was supported by the Beijing Outstanding Young Scientist Program (BJJWZYJH01201910011025) and the National Natural Science Foundation of China (no. 31972191).

\section{Supplementary Materials}

Table S1: the aroma compounds isolated by solvent-assistant evaporation extraction in Litsea pungens Hemsl. fruit. (Supplementary Materials)

\section{References}

[1] H. G. Richter, "Anatomy of the secondary xylem and bark of the Lauraceae," Anatomie des sekundaeren Xylems und der Rinde der Lauraceae, vol. 5, pp. 1-148, 1981.

[2] Z. W. Xie and Y. Q. Yu, The Guide of National Chinese Herbal Medicine, People's Medical Publishing House, Beijing, China, 1996.

[3] D. G. Kong, G. H. Zhao, G. H. Li et al., "The genus Litsea in traditional Chinese medicine: an ethnomedical, phytochemical and pharmacological review," Journal of Ethnopharmacology, vol. 164, pp. 256-264, 2015.

[4] K. L. Mo, "Further processing of litsea cubeba oil and utilization of its deep-processed products," Journal of Sichuan Forestry Science and Technology, vol. 4, pp. 61-65, 2005.

[5] S. P. Zhang and N. Hu, "Application of litsea cubeba oil in synthetic perfumes," Guizhou Chemical Industry, vol. 3, pp. 21-26, 2003.

[6] X. H. Wang, Y. L. Xia, R. Zhao et al., "Development of characteristic flavor chili sauce," China Condiment, vol. 44, no. 4, pp. 136-138, 2019.

[7] D. Ma and L. Wang, "Study on optimizing the technology of compound condiment of Litsea pungens oil spilled chili sauce by orthogonal test," China Condiment, vol. 44, no. 12, pp. 132-135, 2019.

[8] G. S. Tong, K. Z. Huang, T. R. Huang et al., "Effect of Litsea pungens Hemsl. seasoning oil on cold storage quality," China Condiment, vol. 45, no. 10, pp. 59-62, 2020.

[9] Y.-N. Yang, M. Liang, Y. Yang, F.-P. Zheng, X.-P. Wang, and A.-N. Yu, "Optimization of a headspace solid-phase microextraction method for the gas chromatography-mass spectrometry analysis aroma compounds of litsea mollis hemsl. immature fruit," Food Science and Technology, vol. 40, no. 4, pp. 786-793, 2020.

[10] H. J. Zhao, N. Guo, L. X. Yang et al., "Extraction and analysis of volatile components in dried litsea cubeba," Flavour Fragrance Cosmetics, vol. 5, pp. 1-5, 2017.

[11] C. J. Yu, X. P. Song, C. L. Lou et al., "Chemical components of the essential oil in the peel from Hainan Litsea cubeba," Guangzhou Chemical Industry, vol. 41, no. 18, pp. 102-104, 2013.

[12] C. J. Yu, X. P. Song, X. Zhou et al., "Chemical components and antitumor activity of essential oil of Litsea cubeba seed from Hainan," Research and Development of Natural Products, vol. 26, no. 11, pp. 1849-1852, 2014.

[13] L. Zhang, Y. Min, H. Wang et al., "Study of the chemical constitutes of volatile oil from Litsea Euosma Smith," Journal of Anhui Agricultural Science, vol. 37, no. 29, pp. 14183-14193, 2009.

[14] L. J. Yang, G. P. Li, X. D. Yang et al., "Chemical constituents of the volatile oil in the fruits of Litsea Chingpingensis," Analysis and Identification of Traditional Chinese Medicine, vol. 15, no. 19, pp. 1153-1154, 2008.

[15] D. G. Wan and Y. Z. Chen, "Analysis of the chemical constituents of the volatile oil from the fruits of litsea populifolia," Natural Product Research and Development, vol. 2, pp. 136-137, 2004. 
[16] H. P. Chen, H. X. Yin, Y. Q. Liu et al., "Chemical constituents of the volatile oil in the fruits of Litsea mollifofia Chun," Chinese Traditional and Herbal Drugs, vol. 15, no. 11, pp. 13-15, 1984.

[17] T. Y. Qiao, G. L. Ye, P. Liang et al., "Determination of volatile components from fruit of Litsea pungens Hemsl. by SPMEGC-MS," Guangzhou Chemical Industry, vol. 47, pp. 74-76, 2019.

[18] Z. Dong, "Composition analysis and biological activities of the essential oil from Litsea pungens Hemsl," Master's thesis, Wuhan Polytechnic University, Wuhan, China, 2017.

[19] F. S. Wang, S. L. Huang, H. Y. Hu et al., "Molecular distillation purifying technics of citral from essential oil of fruits of litsea mollis and its chemical constituents analysis," Research and Development of Natural Products, vol. 2, pp. 55-57, 2002.

[20] W. Duan, Y. Huang, J. Xiao, Y. Zhang, and H. Zhang, "Comparison of nonvolatile taste components in 18 strong fragrance spices," International Journal of Food Properties, vol. 23 , no. 1 , pp. 340-353, 2020.

[21] W. Duan, Y. Huang, J. Xiao, Y. Zhang, and Y. Tang, "Determination of free amino acids, organic acids, and nucleotides in 29 elegant spices," Food Science \& Nutrition, vol. 8, no. 7, pp. 3777-3792, 2020.

[22] A. Dunkel, M. Steinhaus, M. Kotthoff et al., "Nature's chemical signatures in human olfaction: a foodborne perspective for future biotechnology," Angewandte Chemie International Edition, vol. 53, no. 28, pp. 7124-7143, 2014.

[23] D. Pu, W. Duan, Y. Huang et al., "Characterization of the key odorants contributing to retronasal olfaction during bread consumption," Food Chemistry, vol. 318, p. 126520, 2020.

[24] W. Engel, W. Bahr, and P. Schieberle, "Solvent assisted flavour evaporation-a new and versatile technique for the careful and direct isolation of aroma compounds from complex food matrices," European Food Research and Technology, vol. 209, no. 3-4, pp. 237-241, 1999.

[25] D. D. Pu, H. Y. Zhang, Y. Y. Zhang et al., "Characterization of the key aroma compounds in white bread by aroma extract dilution analysis, quantitation, and sensory evaluation experiments," Journal of Food Processing and Preservation, vol. 43, no. 4, Article ID e13933, 2019.

[26] H. Zhang, D. Pu, B. Sun, F. Ren, Y. Zhang, and H. Chen, "Characterization and comparison of key aroma compounds in raw and dry porcini mushroom (Boletus edulis) by aroma extract dilution analysis, quantitation and aroma recombination experiments," Food Chemistry, vol. 258, pp. 260-268, 2018.

[27] D. Pu, H. Zhang, Y. Zhang et al., "Characterization of the oral breakdown, sensory properties, and volatile release during mastication of white bread," Food Chemistry, vol. 298, Article ID 125003, 2019.

[28] D. D. Pu, W. Duan, Y. Huang et al., "Characterization of the dynamic texture perception and the impact factors on the bolus texture changes during oral processing," Food Chemistry, vol. 339, Article ID 128078, 2020.

[29] O. Sevindik, G. Guclu, G. Bombai et al., "Volatile compounds of cvs Magliocco Canino and Dimrit grape seed oils," Journal of Raw Materials to Processed Foods, vol. 1, pp. 47-54, 2020.

[30] Y. Liu, Q. Li, W. Yang et al., "Characterization of the potent odorants in Zanthoxylum armatum DC Prodr. pericarp oil by application of gas chromatography-mass spectrometryolfactometry and odor activity value," Food Chemistry, vol. 319, Article ID 126564, 2020.

[31] J. Van Gemertl, Odour Thresholds, Oliemans Punter \& Partners B V, Utrecht, Netherlands, 2011.
[32] X. Gong, Y. Han, J. Zhu et al., "Identification of the aromaactive compounds in Longjing tea characterized by odor activity value, gas chromatography-olfactometry, and aroma recombination," International Journal of Food Properties, vol. 20, no. 1, pp. 1107-1121, 2017.

[33] D. D. Pu, Y. Y. Zhang, H. Y. Zhang et al., "Characterization of the key aroma compounds in traditional hunan smoke-cured pork leg (larou, THSL) by aroma extract dilution analysis (AEDA), odor activity value (OAV), and sensory evaluation experiments," Foods, vol. 9, no. 4, p. 413, 2020.

[34] M. Huber and R. Franz, "Identification of migratable substances in recycled high density polyethylene collected from household waste," Journal of High Resolution Chromatography, vol. 20, no. 8, pp. 427-430, 1997.

[35] G. A. Burdock, Fenaroli's Handbook of Flavor Ingredients, CRC Press, Boca Raton, FL, USA, 3rd edition, 1995.

[36] N. Dudareva, F. Negre, D. A. Nagegowda, and I. Orlova, "Plant volatiles: recent advances and future perspectives," Critical Reviews in Plant Sciences, vol. 25, no. 5, pp. 417-440, 2006.

[37] J. Sun, B. Sun, F. Ren, H. Chen, N. Zhang, and Y. Zhang, "Characterization of key odorants in hanyuan and hancheng fried pepper (Zanthoxylum bungeanum) oil," Journal of Agricultural and Food Chemistry, vol. 68, no. 23, pp. 64036411, 2020.

[38] D. D. Pu, Y. Y. Zhang, B. G. Sun et al., "Characterization of the key taste compounds during bread oral processing by instrumental analysis and dynamic sensory evaluation," LWTFood Science Technology, vol. 138, Article ID 110641, 2020.

[39] M. Ashour, M. Wink, and J. Gershenzon, "Biochemistry of terpenoids: monoterpenes, sesquiterpenes and diterpenes," in Annual Plant Reviews Volume 40: Biochemistry of Plant Secondary Metabolism, M. Wink, Ed., Wiley, Chichester, UK, 2010.

[40] M. Gutensohn, D. A. Nagegowda, and N. Dudareva, "Involvement of compartmentalization in monoterpene and sesquiterpene biosynthesis in plants," in Isoprenoid Synthesis in Plants and Microorganisms, T. J. Bach and M. Rohmer, Eds., Springer, New York, NY, USA, 2013.

[41] A. Buettner, Springer Handbook of Odor, Springer, , Berlin, Germany, 2017.

[42] A. Hemmerlin, J. L. Harwood, and T. J. Bach, "A raison d'etre for two distinct pathways in the early steps of plant isoprenoid biosynthesis," Progress in Lipid Research, vol. 51, no. 2, pp. 95-148, 2018.

[43] B. M. Lange, S. S. Mahmoud, M. R. Wildung et al., "Improving peppermint essential oil yield and composition by metabolic engineering," Proceedings of the National Academy of Sciences, vol. 108, no. 41, pp. 16944-16949, 2011.

[44] E. M. Davis and R. Croteau, "Cyclization enzymes in the biosynthesis of monoterpenes, sesquiterpenes, and diterpenes," in Biosynthesis, D. F. J. Leeper and P. D. J. C. Vederas, Eds., Springer, Berlin, Germany, 2000.

[45] W. Schwab, R. Davidovich-Rikanati, and E. Lewinsohn, "Biosynthesis of plant-derived flavor compounds," The Plant Journal, vol. 54, no. 4, pp. 712-732, 2008.

[46] P. Winterhalter, "Generation of norisoprenoid volatiles-recent advances," in Advances and Challenges in Flavor Chemistry and Biology, T. Hofmann, W. Meyerhof, and P. Schieberle, Eds., Deutsche Forschungsanstalt für Lebensmittelchemie, Garching, Germany, 2010.

[47] A. L. Schilmiller, I. Schauvinhold, M. Larson et al., "Monoterpenes in the glandular trichomes of tomato are synthesized from a neryl diphosphate precursor rather than geranyl diphosphate," Proceedings of the National Academy of Sciences, vol. 106, no. 26, pp. 10865-10870, 2009. 